\title{
Principios para la tutela efectiva del patrimonio cultural
}

\author{
Aurora Villalobos Gómez | Consejería de Cultura y Patrimonio Histórico, Junta de Andalucía
}

URL de la contribución <www.iaph.es/revistaph/index.php/revistaph/article/view/4710>

El patrimonio es una construcción social por la que las personas se identifican con determinados bienes del pasado que quieren disfrutar en el presente y conservar para el futuro. Su tutela comprende las acciones de protección, documentación, investigación, conservación, exposición y difusión de los bienes culturales, necesarias para garantizar no solo la salvaguarda de su materialidad sino especialmente sus valores culturales. En cambio, la gestión abarca los procesos de planificación, diseño, ejecución, seguimiento y evaluación de una acción, que puede ser o no de tutela. Es por ello que en esta aportación se diferencia entre tutela y gestión, considerando que la segunda está implícita en los procesos de cada una de las acciones que definen la primera.

De entre las instituciones patrimoniales encargadas de la tutela de los bienes culturales destaca el museo por ser "una institución sin fines lucrativos, permanente, al servicio de la sociedad y de su desarrollo, abierta al público, que adquiere, conserva, investiga, comunica y expone el patrimonio material e inmaterial de la humanidad y su medio ambiente con fines de educación, estudio y recreo" (ICOM, 2007). Su misión supera la delimitación convencional entre bienes materiales/inmateriales, culturales/naturales y muebles/inmuebles con una visión holística e integradora que permite entender como tal las instituciones que tutelan espacios culturales.

Para que toda acción patrimonial sea representativa y coherente con los valores culturales de los bienes se proponen los siguientes principios metodológicos:

1. INTEGRAR las dimensiones del patrimonio como monumento (valor estético), documento (valor científico), identidad (valor simbólico) y recurso (valor económico); de manera que el reconocimiento cultural de un bien sea más evidente en la medida en que converjan más dimensiones patrimoniales.
2. ATENDER a los cambios que demanda un concepto social del patrimonio en permanente transformación ya que el proceso de identificación de los bienes culturales está relacionado con la elección y justificación de valores, más que con una propiedad intrínseca del bien. Entre la memoria y la contemporaneidad, ser conscientes de que inevitablemente toda aproximación al pasado se hace desde el presente y que, asimismo, nuestra época dejará su huella.

3. CONCILIAR la conservación de los bienes culturales y las prestaciones a los usuarios, dando prioridad a la salvaguarda de los valores culturales ya que las necesidades planteadas por los usuarios son variables y permiten soluciones alternativas desde el diseño para todos.

4. SITUAR a las personas en el centro de la acción patrimonial, considerando que el patrimonio es un recurso, sostenible pero no renovable, capaz de dotar de identidad dentro de la diversidad y de generar cohesión social por su enorme potencial para cualificar la vida de las personas.

5. CREAR sinergias con todos los agentes implicados, desde la corresponsabilidad: comprometiendo en la gestión a las administraciones públicas (sobre todo las locales, por su proximidad a los bienes y personas), valorizando los profesionales especializados (porque el intrusismo y el voluntarismo perjudican por igual) y educando a la ciudadanía (para que su participación en los procesos patrimoniales sea crítica y constructiva). En verdad todos somos ciudadanía porque los profesionales son ciudadanos con una formación cualificada y las administraciones públicas son ciudadanos que conforman un cuerpo de profesionales comprometidos con el servicio público que actúan desde los principios de necesidad, eficacia, proporcionalidad, seguridad jurídica, transparencia y eficiencia.

6. IMPULSAR actuaciones en coordinación con otros sectores tales como turismo (ofreciendo experiencias 
a debate Hacia una nueva institucionalidad cultural. Modelos emergentes de gestión...

| coordina Jesús Carrillo Castillo

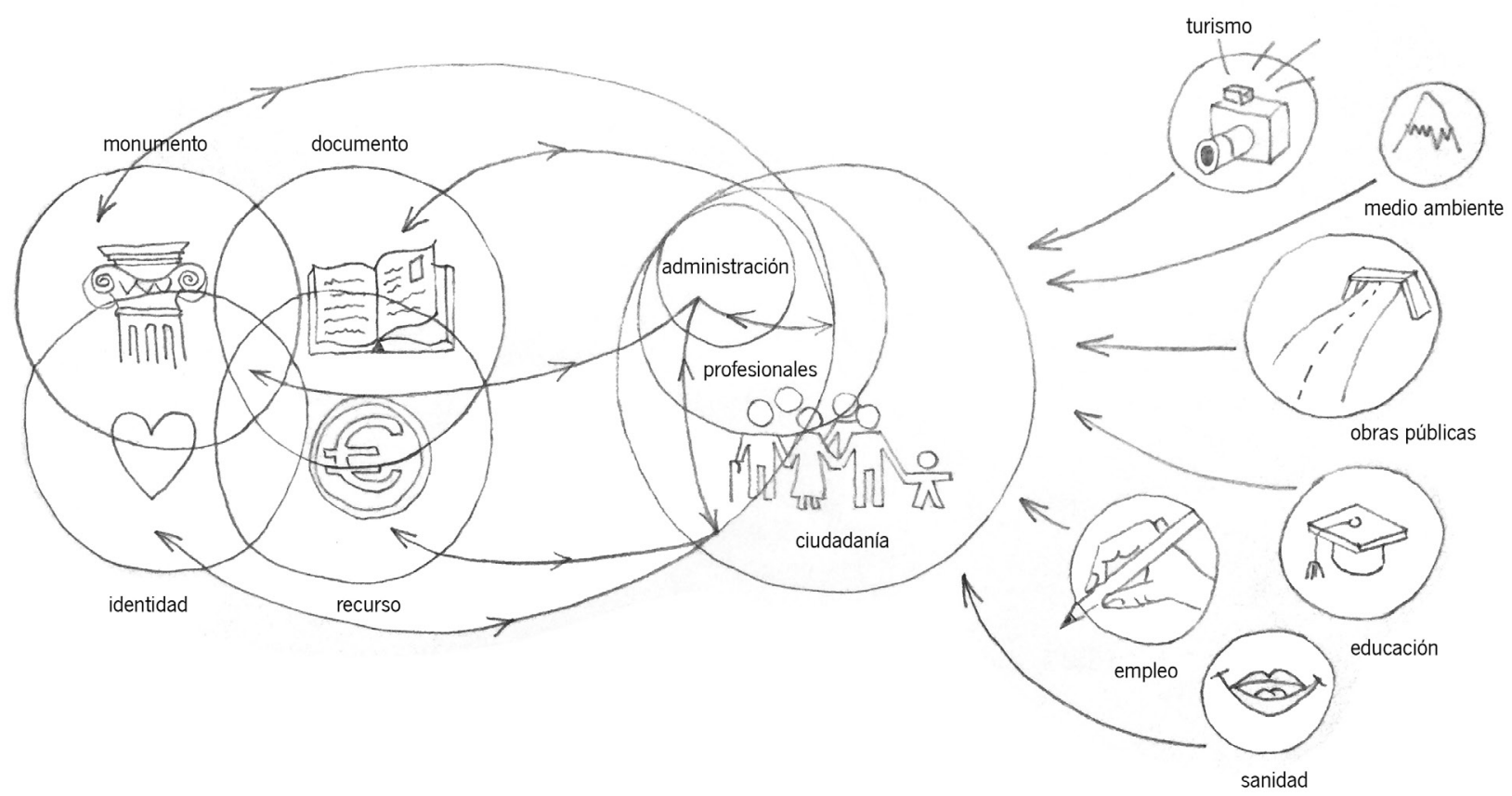

Modelo de tutela del patrimonio cultural | ideograma Aurora Villalobos Gómez, 2020

culturales de calidad), obras públicas (creando nuevos itinerarios culturales que eviten la despoblación del territorio), medio ambiente (compartiendo criterios para conservar nuestros paisajes antropizados), empleo (apoyando las profesiones especializadas en patrimonio), educación (incorporando entre las asignaturas el conocimiento del patrimonio, desde una perspectiva que supere el enfoque localista), sanidad (reconociendo la contribución de la cultura al bienestar físico y emocional de las personas)...

7. PLANIFICAR las actuaciones de tutela a medio/largo plazo para que lo urgente no nos haga olvidarnos de lo importante. Esto supone fijar objetivos, consensuar criterios, asignar funciones y coordinar acciones a través de planes-programas-proyectos que tengan continuidad más allá de las legislaturas.

8. EVALUAR las actuaciones para optimizar recursos y generar Valor Público, entendido como una mejora de la calidad de vida de las personas.
9. TRANSFERIR conocimientos y buenas prácticas entre los profesionales y administraciones, a partir del trabajo en redes especializadas e interdisciplinares. La investigación debe ser la base de las demás acciones de tutela, entendida no como el discurso científico que institucionaliza una determinada línea de pensamiento, sino como la presentación de una cultura material o inmaterial.

10. DIVULGAR los procesos y las acciones de tutela para ir generando una cultura patrimonial libre y responsable.

En este modelo de tutela (el qué y para qué) son posibles y deseables nuevos modelos de gestión (el cómo) que consoliden una estrategia transversal de continuo diálogo. Esa denominada 'democracia cultural' requiere un esfuerzo previo de educación patrimonial porque "en un Estado democrático estos bienes deben estar adecuadamente puestos al servicio de la colectividad en el convencimiento de que con su disfrute se facilita el acceso a la cultura y que ésta, en definitiva, es camino seguro 
hacia la libertad de los pueblos" (Ley del Patrimonio Histórico Español, 1985: preámbulo).

De esta manera la ciudadanía no se sentirá tratada como una mera destinataria o consumidora de productos culturales sujetos al cambio de gusto o intereses ideológicos, sino que se implicará activamente, a nivel personal o colectivo, en un patrimonio vivo que siente propio: cumpliendo de buen grado las obligaciones de conservación y apertura al público que conlleva ser propietario de un bien cultural, comportándose de manera cívica como usuario de las instituciones, cuidando de su paisaje cultural, recurriendo a profesionales especializados, informando de los hallazgos casuales, participando en las consultas públicas, colaborando en actividades culturales, aprendiendo y compartiendo miradas...

Asimismo es imprescindible que las profesiones vinculadas al patrimonio cultural puedan trabajar en un marco legislativo claro respecto a los itinerarios formativos, el ámbito de competencias y la regulación de su actividad, como requieren los conservadores-restauradores, arqueólogos, paleontólogos o intérpretes. Solo así podremos hablar de una verdadera industria cultural que se encargue de "la creación, la producción y la comercialización de contenidos creativos, los cuales son intangibles y de naturaleza cultural. Los contenidos se encuentran protegidos por derechos de autor y pueden tomar la forma de bienes o servicios" (UNESCO, 2006: 3). La mayoría de los profesionales son autónomos e investigadores de grupos universitarios, normalmente en precario. El futuro está en los perfiles híbridos y las nuevas profesiones que estén por venir. El patrimonio debería empezar a entenderse como un sector esencial porque la cultura es la que nos sostiene como sociedad ante crisis como la que estamos viviendo actualmente.

Por último, la administración no puede entenderse como un ente indiferenciado que se confunde con implacables y tediosos procesos administrativos sino que debiera percibirse como empleados públicos, motivados e innovadores que trabajan por el bien común, a pesar de la falta de medios; por ejemplo, estableciendo las bases legales para el mecenazgo o haciendo de la contratación pública un instrumento dinamizador a través de cláusulas sociales y medioambientales.

La revisión de la definición de 'museo' propuesta por ICOM pone en evidencia las inquietudes planteadas en este debate, como un signo de madurez patrimonial: "Los museos son espacios democratizadores, inclusivos y polifónicos para el diálogo crítico sobre los pasados y los futuros. Reconociendo y abordando los conflictos y desafíos del presente, custodian artefactos y especímenes para la sociedad, salvaguardan memorias diversas para las generaciones futuras, y garantizan la igualdad de derechos y la igualdad de acceso al patrimonio para todos los pueblos. Los museos no tienen ánimo de lucro. Son participativos y transparentes, y trabajan en colaboración activa con y para diversas comunidades a fin de coleccionar, preservar, investigar, interpretar, exponer, y ampliar las comprensiones del mundo, con el propósito de contribuir a la dignidad humana y a la justicia social, a la igualdad mundial y al bienestar planetario" (ICOM, 2019).

\section{BIBLIOGRAFÍA}

- ICOM (2007) Definición actual de 'museo' [en línea] <https:// icom.museum/es/recursos/normas-y-directrices/definicion-delmuseo/> [Consulta: 01/07/2020]

- ICOM (2019) Propuesta oficial de nueva definición de 'museo' [en línea] <https://icom.museum/es/news/el-icomanuncia-la-definicion-alternativa-del-museo-que-se-someteraa-votacion/> [Consulta: 01/07/2020]

- Ley 16/1985, de 25 de junio, del Patrimonio Histórico Español (1985) Boletín Oficial el Estado, n. ${ }^{\circ}$ 155, de 25 de junio <https://www.boe.es/eli/es/l/1985/06/25/16/con> [Consulta: 01/07/2020]

- UNESCO (2006) Understanding Creative Industries: Cultural Statistics for Public-Policy Making. Global Alliance for Cultural Diversity [en línea] <https://wayback.archive-it. org/10611/20161115110708/http://portal.unesco.org/culture/ en/files/30297/11942616973cultural_stat_EN.pdf/cultural_ stat_EN.pdf> [Consulta: 01/07/2020] 